\title{
STUDY ON THE PREVALENCE OF PULMONARY TUBERCULOSIS AMONG HIV POSITIVE ATTENDING HIV CLINICS IN EASTERN NEPAL
}

\author{
Yadav DK' ${ }^{1}$, Jha N ${ }^{2}$, Pokharel PK ${ }^{3}$, Niraula SR ${ }^{4}$, Bhattacharya SK ${ }^{5}$, Nagesh S $^{6}$ \\ 1,2,3,4 School of Public Health \& Community Medicine, BPKIHS, Dharan \\ 5 Department of Microbiology, Faculty of Medicine, BPKIHS, Dharan \\ 6 Lady Harding Medical College, New Delhi, India
}

\begin{abstract}
Background: Tuberculosis (TB) is an infectious disease caused by Mycobacterium tuberculosis. More than 2 billion people are infected with TB bacilli worldwide. It is a leading public health problem particularly in the developing countries. The HIV epidemic has increased the global tuberculosis burden. TB is the commonest opportunistic infection and leading cause of mortality of People living with HIV (PLHA). Tuberculosis is a major public health problem in Nepal. The objective of the study is to determine prevalence of Pulmonary Tuberculosis among HIV positives attending HIV clinics in Eastern Nepal, and to assess the socio-demographic factors associated with TB and HIVIAIDS.

Methodology: Cross-sectional prospective study was carried out among HIV positive attending different VCT and HIV clinics from Sunsari Morang and Jhapa district of Eastern Nepal. Face to face interview was performed and sputum sample were collected using convenience sampling technique. Data was collected from PLHA on related information on Socio-demographic profile, risk taking behavior with the help of pretested semi-structured questionnaire. Univariate and bivariate analysis were performed using SPSS 15.0. Chi-squire test was performed to establish statistical significance between dependent and independent variables.
\end{abstract}

Results: Out of total 242 PLHA, $75.2 \%$ were males and $24.8 \%$ females; around half of them (48.8\%) were in the age group of (30-39) yrs, $23 \%$ in (25-29) yrs, and $15.7 \%$ in (20-24) years. Prevalence of pulmonary tuberculosis was found to be $27.3 \%(n=66)$. PTB was high among IDU's $(48.6 \%)$, followed by clients of CSWs (21\%), housewife (13.6\%), highway truck drivers (10.6\%) and CSWs (6\%).

Conclusion: Prevalence of PTB is very high among PLHA attending VCT \& HIV clinics of Eastern Nepal. This study reveals that PTB is significantly associated with increasing age, risk taking behavior and place of residence. There is urgent need of active case finding as well as periodic screening among people living with HIVIAIDS of this region to address HIV-associated TB morbidity and mortality.

Keywords: Tuberculosis, PTB, HIV, TB/HIV co-infection, Dharan, Eastern Nepal

\section{INTRODUCTION}

Tuberculosis (TB) is an infectious disease caused by Mycobacterium. More than two billion people,

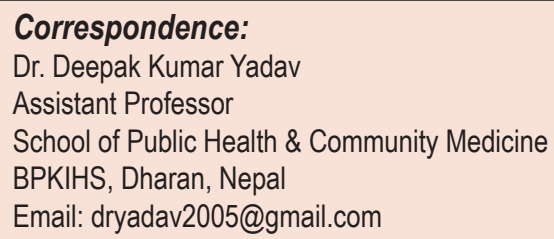

equal to one-third of the world's population, are infected with TB bacilli. It is a leading public health problem worldwide particularly in the developing countries. There are about 9 million estimated new cases of TB occurring globally each year. ${ }^{1}$ Tuberculosis is a major public health problem in Nepal, being endemic area for TB where more than $45 \%$ population is infected. ${ }^{2}$ TB is more common among reproductive age group (15-49yrs). Out of 
40,000 new TB cases reported each year in Nepal, 20,000 are infectious. ${ }^{2}$ HIVIAIDS has emerged as one of the major problem within South East Asian Countries, revealing low general population prevalence rate, but with concentrated epidemic. Nepal as a SAARC country is ripe with vulnerability due to high risk behavior groups. ${ }^{3}$

The HIV epidemic has increased the global tuberculosis burden. Estimating the proportion of HIV infection among TB cases can act as early warning system for the spread of TB due to HIV in the country. HIV infection makes an infected person more susceptible to both pulmonary and extra pulmonary forms of TB. ${ }^{4-6}$ Compared to an individual without HIV infection, HIV infected patients are up to 10 times as likely to develop TB. ${ }^{7}$ Among the different opportunistic infection (Ols), tuberculosis is the most common in HIVIAIDS accounting for $40 \%$ deaths in Africa and South East Asia. ${ }^{6}$ Various studies have documented the occurrence of TB among HIV infected patients ranging from 46 to 80 percent. $^{8}$ In 1998, it was observed in Nepal that out of fourteen AIDS cases, 11 (78.5\%) had tuberculosis, whereas during 1998-2002, out of 442 AIDS cases 357 (80.4\%) had TB. ${ }^{9}$ Similar study in 2001-2002, from western Nepal observed that out of 81 HIV seropositive 28 $(34.6 \%)$ had tuberculosis. ${ }^{10}$

Collaboration between TB and HIVIAIDS program is essential in order to tackle the dual burden of the disease. Despite the formulation of policies and strategies of TB/HIV collaboration in Nepal, there's a lack of strong evidence to illustrate the exact situation of the collaborative activities at implementation level. TB HIV coordinating authorities with clearly defined terms need to be established at all levels of the district to achieve effective collaboration between existing HIV AIDS and TB programmes. ${ }^{11}$ The objective of the study was to determine prevalence of Pulmonary Tuberculosis among HIV positive patients attending HIV clinics in Eastern Nepal, and to assess the socio-demographic factors associated with TB and HIVIAIDS.

\section{METHODOLOGY}

This cross-sectional prospective study was carried out in Sunsari, Morang, and Jhapa districts of Eastern region of Nepal, among an HIV infected cohort. The representative sample was collected to find out burden of pulmonary tuberculosis using active case finding in different community level VCT and STI/HIV clinics. Among a total of 900 high risk population $242 \mathrm{HIV}$ positives were included in the study. Convenience sampling technique was applied to know the prevalence of PTB among HIV positive population within one year of the study period.

Data was collected from below mentioned centers with the help of community mobilizers, peer groups and some volunteers. They were mobilized in community to identify risk behavior group of people by using snowball technique and refer them up to VCT and STI centers where further testing for HIV status was done and investigated for Pulmonary TB.

Data was collected from following centers - VCT/ HIV clinic of BPKIHS, Dharan Positive Group (DPGs), KYC Punarjeevan Kendra Dharan, Mobile VCT and STI Management clinic of SIDC (Society Improvement and Development Centre) Dharan, Ithari, Inaruwa, Biratnagar of Sunsari and Morang district, similarly from Blue Diamond Society Ithari, Morang AIDS-PLWH Society (MAPS), Nav Kiran Plus Biratnagar, VCT \& STI center of Damak, \& Labh Kush Aasharam Chandragadhi, Jhapa.

\section{Data collection and management}

All the subjects were interviewed separately and confidentiality was maintained. Questions were asked in local language and recorded in English language. Three specimen of sputum (One early morning and another two on spot) were collected and processed at TB research laboratory, BPKIHS. Acid Fast Bacilli (AFB) were observed by ZiehlNeelsen (Z-N) staining, and the number of bacilli $(1+, 2+, \& 3+)$ was graded according to guidelines 
of National Tuberculosis Center (NTC), Nepal. All sputum positive cases were provided anti tuberculosis treatment from nearest DOTS center and sub centers.

\section{Data analysis}

Data were entered in to Microsoft office Excel 2003 and univariate and bivariate analysis were performed with software SPSS version 15.0. Chi-square test was used to test the significance between the categorical variables. Probability of significance was set at $5 \%$ level of significance.

\section{Ethical considerations}

The study was conducted after acceptance by ethical committee of B.P. Koirala Institute of Health Sciences. Before conducting the study a written permission was taken from following NGO/ INGO; Society Improvement and Development Centre (SIDC), Asian Medical Doctors Association (AMDA), Kirat Yakthum Chumblung-Punarjeewan Kendra (KYC-PJK), Sahara Nepal, and Blue Diamond Society (BDS). Verbal and written consent was obtained from each participant and confidentiality was maintained.

\section{RESULTS}

Among the total of two hundred forty two HIV seropositive cases, male to female ratio was 3:1 and majority (48.8\%) were between $30-39$ yrs age group. The prevalence of pulmonary tuberculosis was found to be $27.3 \%$ (Figure 1).

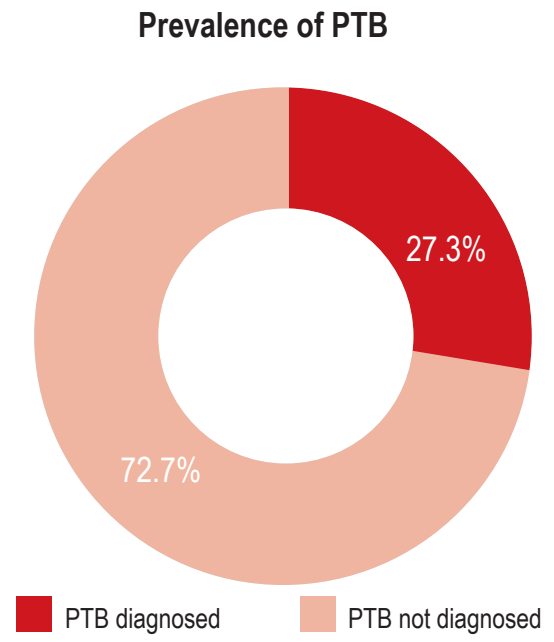

Figure 1. Prevalence of pulmonary tuberculosis among the HIV positive attending HIV clinics in Eastern Nepal

The study population had been ethnically divided into five categories (Table 1). More than $40 \%$ of the populations were from the Major Hill Caste $(\mathrm{MHC})$, $38 \%$ belonged to the Hill Native Caste (HNC), $5.4 \%$ Terai Middle Caste (TMC), and $9.1 \%$ Terai occupational Caste (TOC). Sixty three percent of them were Hindus followed by Buddhist/Kirat/ Christians (34\%) and around 2\% Muslim. In terms of marital status, $55.4 \%$ were married, $15.3 \%$ separated/divorced and $5 \%$ widows/widower. Half of them $(51.7 \%)$ were from Sunsari, $30.2 \%$ from Jhapa and $18.2 \%$ from Morang district. In terms of migration, $10.3 \%$ migrated from hill and $10.7 \%$ from terai. Majority (68.6\%) of the subjects migrated for the job where rest was for travels $(17.6 \%)$ and education (13.7\%). More than Ninety $(90.5 \%)$ percent were literate. Large proportions $(21 \%)$ of the participants were skilled laborer,

\begin{tabular}{|lrrr|}
\hline \multicolumn{4}{|l|}{ Table 1. Socio-Demographic characteristics and PTB among the study population } \\
\hline \multicolumn{3}{|l|}{ Study population HIVIAIDS ( $\mathbf{n = 2 4 2 )}$} & \\
\hline Gender & Total No (\%) & PTB +ve No (\%) & P value \\
\hline Male & $182(75.2)$ & $52(28.6)$ & 0.429 \\
Female & $60(24.8)$ & $14(23.3)$ & \\
\hline Age in years & & & \\
\hline $0-19$ & $10(4.1)$ & $2(20.0)$ & \\
$20-24$ & $38(15.7)$ & $8(21.0)$ & \\
$25-29$ & $56(23.1)$ & $13(23.2)$ & \\
$30-39$ & $118(48.8)$ & $35(29.7)$ & \\
40 yrs and above & $20(8.3)$ & $8(40.0)$ & \\
\hline
\end{tabular}


Table 1. Continuous

\begin{tabular}{|c|c|c|c|}
\hline \multirow{2}{*}{$\begin{array}{l}\text { Characteristics } \\
\text { Caste/ Ethnicity * }\end{array}$} & \multicolumn{3}{|c|}{ Study population HIV/AIDS $(n=242)$} \\
\hline & \\
\hline $\begin{array}{l}\text { Major Hill Caste(MHC) } \\
\text { Hill Occupational Caste(HOC) } \\
\text { Hill Native Caste(HNC) } \\
\text { Terai Middle Caste(TMC) } \\
\text { Terai Occupational Caste(TOC) }\end{array}$ & $\begin{array}{r}97(40.1) \\
14(5.8) \\
92(38.0) \\
13(5.4) \\
26(10.8)\end{array}$ & $\begin{array}{r}26(27.4) \\
2(40.0) \\
26(28.3) \\
9(24.3) \\
3(23.1)\end{array}$ & 0.947 \\
\hline \multicolumn{4}{|l|}{ Religion } \\
\hline $\begin{array}{l}\text { Hindu } \\
\text { Others(Kirat/Buddhist/Christians) }\end{array}$ & $\begin{array}{r}154(63.6) \\
88(46.4)\end{array}$ & $\begin{array}{l}46(29.9) \\
20(22.7)\end{array}$ & 0.230 \\
\hline \multicolumn{4}{|l|}{ Marital status } \\
\hline $\begin{array}{l}\text { Unmarried } \\
\text { Married } \\
\text { Widows / widower \& } \\
\text { Separated / Divorced }\end{array}$ & $\begin{array}{r}59(24.4) \\
134(55.4) \\
49(20.3)\end{array}$ & $\begin{array}{l}38(28.4) \\
14(23.7) \\
14(28.6)\end{array}$ & 0.014 \\
\hline \multicolumn{4}{|l|}{ Place of residence } \\
\hline $\begin{array}{l}\text { Sunsari } \\
\text { Morang } \\
\text { Jhapa }\end{array}$ & $\begin{array}{r}125(51.7) \\
44(18.2) \\
73(30.2)\end{array}$ & $\begin{array}{r}32(25.6) \\
3(6.8) \\
31(42.5)\end{array}$ & 0.001 \\
\hline \multicolumn{4}{|l|}{ Migration status } \\
\hline $\begin{array}{l}\text { Not migrated } \\
\text { Migrated from } \\
\text { Hill district } \\
\text { Terai district }\end{array}$ & $\begin{array}{l}191(78.9) \\
25(10.3) \\
26(10.7)\end{array}$ & $\begin{array}{r}49(25.7) \\
6(24.0) \\
11(42.3)\end{array}$ & 0.187 \\
\hline \multicolumn{4}{|l|}{ Literacy } \\
\hline $\begin{array}{l}\text { Illiterate } \\
\text { Literate } \\
\text { School education(Primary) } \\
\text { Up to class ten(Secondary) } \\
\text { SLC and above }\end{array}$ & $\begin{array}{r}23(9.5) \\
170(70.2) \\
37(15.5) \\
12(5.0)\end{array}$ & $\begin{array}{r}8(34.8) \\
42(24.7) \\
13(35.1) \\
3(25.0)\end{array}$ & 0.493 \\
\hline \multicolumn{4}{|l|}{ Occupational status } \\
\hline $\begin{array}{l}\text { Agriculture } \\
\text { Business / sales } \\
\text { Professional / Administrative } \\
\text { Skilled laborer } \\
\text { Unskilled laborer } \\
\text { Unemployed (Housewife,\& Student) }\end{array}$ & $\begin{array}{r}16(6.6) \\
23(9.5) \\
21(8.7) \\
53(21.9) \\
39(16.1) \\
90(37.1)\end{array}$ & $\begin{array}{r}4(25.0) \\
13(56.5) \\
4(19.0) \\
16(30.2) \\
12(30.8) \\
17(18.9)\end{array}$ & 0.014 \\
\hline \multicolumn{4}{|l|}{ Income per month } \\
\hline $\begin{array}{ll}\text { Less than } & \text { Rs. 2,250 } \\
\text { Between } & \text { Rs. 2,251-5,000 } \\
\text { More than } & \text { Rs. 5,000 }\end{array}$ & $\begin{array}{r}118(48.8) \\
107(44.2) \\
17(16.1)\end{array}$ & $\begin{array}{r}30(25.4) \\
31(29.0) \\
5(29.4)\end{array}$ & 0.081 \\
\hline
\end{tabular}

*MHC included Brahmins, Chhetris, and Newar. HOC included people were kami (Bishwakarma), Damai, Sarki, etc. Similarly HNC included people of Mongolian origin such as Rai, Limbu, Magar, Gurung, and Tamang. TMC included Shah, Thakur, Mandal, Mehta, Tharu (Rajbanshi), Yadav, Singh. TOC included Mushar, Khatbe, Jhagar, Mallik. 
followed by unskilled laborer $16.1 \%$, housewife $12.8 \%$, business/sales $9.5 \%$, police/army $2.5 \%$, agriculture $6.6 \%$ and students $1.2 \%$. On the basis of poverty line in Nepal, the study population has been grouped into three levels of income. Majority of the study population had income less than Rs. 2250 (48.8\%), 44.2\% between Rs. 2251-5,000 and only $16.1 \%$ earn above Rs. $5,000 /$.

The prevalence of PTB among males $(28.6 \%)$ was higher than female population (23.3\%). Similarly it was higher in Hindus (29.9\%) than other religions (22.7\%). PTB was high among HNC (43\%) and MHC $(37.3 \%)$ \& nearly $13 \%$ was observed in TMC. In relation to PTB and migration status, those migrated from terai were significantly higher (42.3\%) than hill districts (24\%).

PTB among literate having secondary education was slightly higher (35.1\%) than among illiterate $(34.8 \%)$. It was similar in subjects who studied more than SLC (25\%) and primary education $(24.7 \%)$. The difference was not significant among both groups. But the prevalence of PTB was found to be higher among subjects related with business/ sales $(56.5 \%)$, whereas the subjects involved in agriculture had low prevalence (25\%), followed by unskilled laborers (30.8\%) skilled laborers $(30.2 \%)$, unemployed $(18.9 \%)$ and professional ladministration (19\%). The difference was statistically significant. In terms of marital status PTB among married was $23.7 \%$ but no significant difference was observed between widower/ divorced (28.6\%) and unmarried (28.4\%). PTB in relation to economic status, it was found that $29 \%$ among those who had income between Rs. 2251 - 5, 000 and similar (29.4\%) with income more than $5,000 /$ - but lower $(25.4 \%)$ prevalence was observed with income below Rs.2,250/- .

PTB was high amongst drivers (46.7\%), almost similar in CSWs (33.3\%) and in Clients of CSWs (33.3\%). However the difference was not significant. In case of smoking habit, the prevalence of PTB was slightly higher (29.2\%) in non smokers than smokers $(26.6 \%)$. Majority of the PTB positive cases (8.8\%) had knowledge about TB while only few of them (1.6\%) didn't have knowledge about TB. PTB positive cases who had been in contact with PTB showed high prevalence (11.1\%) than those who did not have contact with PTB (6.2\%). The prevalence was high (43.3\%) among HIV with PTB positive group having past history of TB. The difference was highly significant. A direct association between PTB positivity and duration of HIV infection was observed. Subjects who were recently infected with HIV showed low prevalence of PTB $(8 \%)$, in comparison to infection more than five yrs had higher $(24.4 \%)$ and those infected for more than five yrs had $37.2 \%$. The difference was significantly high $(p<0.005)$. More than half of study population 129(53\%) were IDUs, whereas $17 \%$ clients of CSWs, and 5\% CSWs. MSMs were found not to be infected with HIVIAIDS. Among the study subjects, majority (38.9\%) of IDUs were unmarried (Figure 2). The proportion of widow/ separated were higher among CSWs (34.2\%) whereas lowest (6.8\%) among drivers. Most of the clients of CSWs were found to be married (34.7\%).

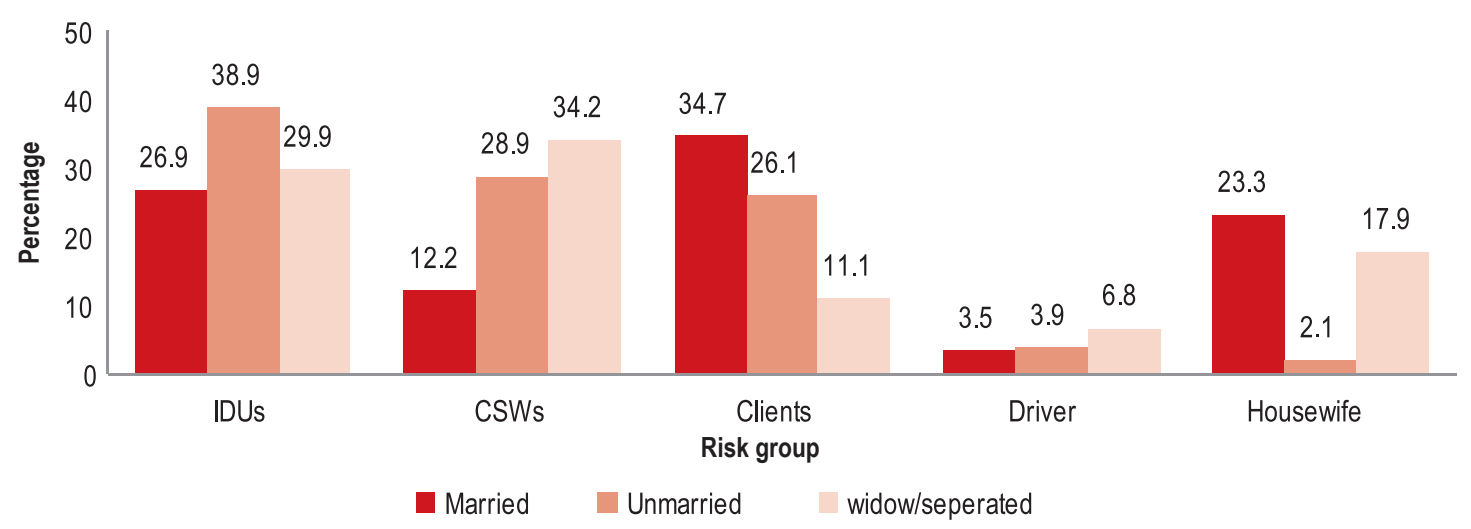

Figure 2. Distribution of the possible risk of HIV transmission according to marital status 


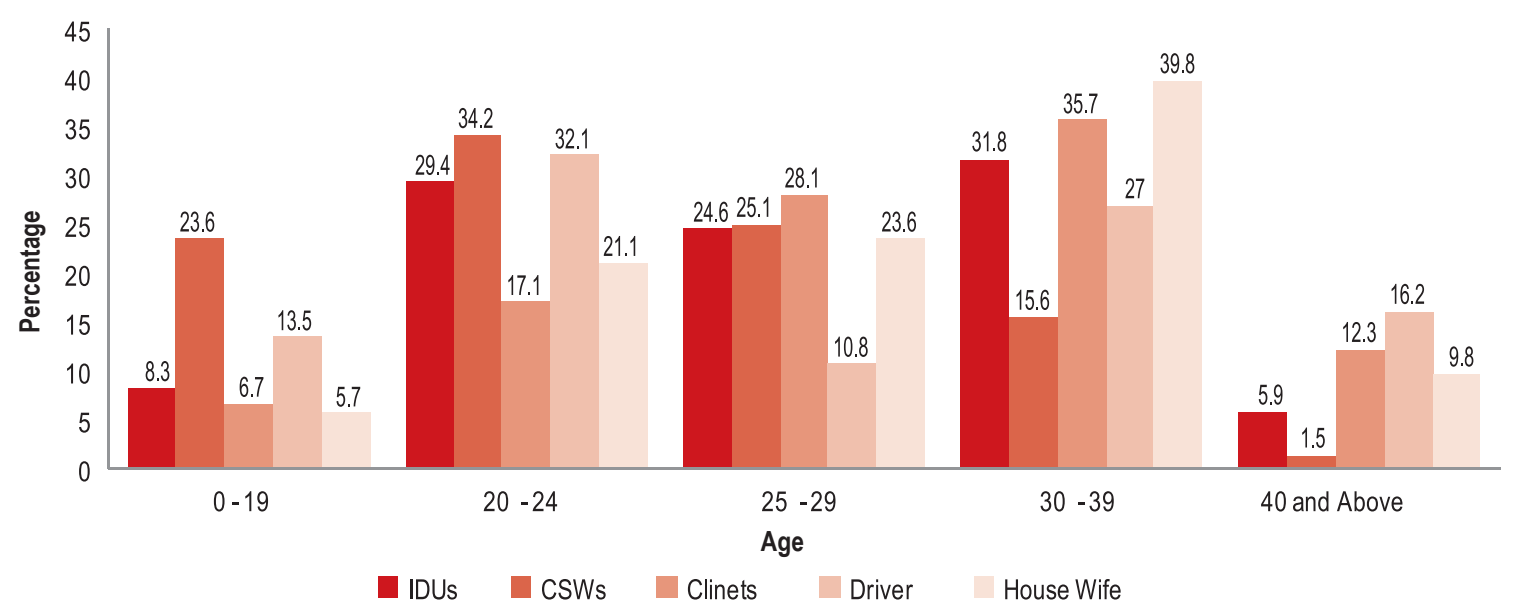

Figure 3. Distribution of the possible risk of HIV transmission with age interval of participants

Distribution of the possible risk of HIV transmission, majority were housewife $(39.8 \%)$, spouse of risk group people, followed by IDUs(31.8\%), clients of CSWS (35.7\%), and drivers (27\%) were in the age group of 30-39 yrs while opposite result was found in case of CSWs, majority (34.2\%) were 20 24 years (Figure 3 ).

\section{DISCUSSION}

In this cross-sectional study, a total number of 242 subjects were enrolled during the study period. The gender of the study population constituted of $75.2 \%$ male and $24.8 \%$ female. This study is supported by a study done at United Mission Hospital Tansen (UMHTP Ghimire et al, ${ }^{10}$ in which the corresponding percentages were $75 \%$ male and $25 \%$ female, another study by Dhungana GP et al showed $66 \%$ male and $34 \%$ female the reason may be study population were only from HIV clinic based with or without undergoing antiretroviral therapy in Kathmandu. The prevalence of PTB among HIV positives in our study was found to be $27.3 \%$. A study done by P. Ghimire et al during 2001-2002 in Tansen Mission Hospital, ${ }^{10}$ showed slightly higher prevalence $(34.6 \%)$ of PTB among HIV positives. The reason may be the subjects of this study was more heterogeneous and constituted new cases from community with active case finding among high risk groups. Similar result was found in the study done in Kolkata (India) by M.K. Bhattacharya et $\mathrm{al}^{12}$, which showed, $24.17 \%$ PTB among HIV positives. National survey of Nepal 1991-2000, documented 312 tuberculosis patients in 473 AIDS cases i.e. $66 \%$ co-infection. ${ }^{9}$

The study revealed that majority of HIV positive subjects were in the age group of 30-39 years (48.8\%) among them $29.7 \%$ found to be PTB positive. The PTB prevalence had an increasing trend with the increase of age interval. The Prevalence of PTB was 20\% in age group (0-19) years, $21 \%$ in $(20-24)$ years, $23.2 \%$ in $(25-29)$ years, $29.7 \%$ in (30-39) years and $40 \%$ in 40 years and above. Similar findings, $P$ Ghimire et al, reported HIVIAIDS cases were around $40 \%$ age group of (21-30) years, $45.7 \%$ in (31-40) years, $9.8 \%$ in(41-51)years, and $4.9 \%$ in age group of (51 yrs and above). Sixty percent TB/HIV co-infected belonged to the age group (31-40) years, $35.7 \%$ of subjects was belonged to age group (21-30) years.

Social demographic characteristic of the study population showed that proportion of PTB varied among the ethnic groups, it was high among MHC (39.4\%) and HNC (39.4\%) \& TMC (13.6\%) followed by TOC (4.5\%) and HOC (3\%). This study showed the proportion of PTB was high in hill native caste which included people of Mongolian origin such as Rai, Limbu, Magar, Tamang. Most of the study subjects were from Sunsari (51.7\%), followed by Jhapa $(30.2 \%)$ and Morang (18.2\%) district. A low degree of migration was noted in this study, migration from terai district was $10.7 \%$ followed by hill district $10.3 \%$. The reason behind migration 
was found to be unemployment, education and travel.

The risk behaviors of the study population demonstrated that IDUs were $32.1 \%$, spouse of HIV positive (housewife) 13.1\%, CSWs 19.2\%, clients of CSWs $28 \%$ and $4.1 \%$ truck drivers. Similar findings were observed by Dhungana GP et al study, which showed 39\% Injecting Drug users (IDUs), $51 \%$ heterosexual activities and $6 \%$ homosexual. The reason for high burden of HIV among IDUs and their wife's might be sharing (exchange) of needles among them and infection might be transmitted to their spouse with unprotected sexual practice of migrated husbands.

Another important finding in case of inhabitance, 42.5\% PTB were from Jhapa district whereas $25.6 \%$ from Sunsari and only 6.8\% from Morang whereas out of total study population $51.7 \%$ were from Sunsari, $30.2 \%$ Jhapa and only $18.2 \%$ from Morang. The possible reason could be more vulnerable people of HIV (IV drugs users, drivers, CSWs) and low coverage of health program for early TB case finding in Jhapa district and might be neglected many HIV positives. The IDUs have more risk of TB infection many of them may suffering from malnutrition and weak immune-status, so they have a high chance of getting TB due to TB-HIV Co-infection.

\section{CONCLUSION}

Among the study population majority of them were male $(75.2 \%)$ where $28.6 \%$ found PTB positive, around $50 \%$ were in age group 30-39 years of whom $29.7 \%$ were Pulmonary Tuberculosis. More than one third of the study population belonged to MHC and HNC. Majority (63.6\%) of study population belonged to Hindu religion. Around $69 \%$ of subjects were migrated for job or work purpose. Majority $(90.5 \%)$ of the subjects were literate, very few were illiterate. A large section (21.9\%) of study population was skilled laborers and unemployed were $37.1 \%$. The majority were married (55.4\%).
This study reveals that PTB is significantly associated with increasing age, place of residence and high risk behaviors. Significant association is observed between PTB and marital status, knowledge of TB, contact with PTB and duration of $\mathrm{HIV}$ infection among risk group. There is significant association between PTB status and occupation, marital status and duration of HIV infection. There is an urgent need of screening program in the districts of eastern Nepal as well as periodic health check up program for early detection of tuberculosis and treatment. Following recommendations are made based on present finding:

1. This study has revealed the fact that PTB is the emerging health problem among HIVIAIDS cases. Therefore, the more detailed parameters and longitudinal studies need to be carried out in eastern region of Nepal.

2. Further case-control study is recommended to identify risk factors and behaviors among the subjects.

\section{REFERENCES}

1. WHO, Regional Office for South-East Asia New Delhi, Tuberculosis control in the South East Asia region, The Regional Report, November 2005, WHO project no. ICP TUB 001:1-2

2. Department of Health Services, Nepal. Annual Health Report 2006/2007.

3. Bam DS, Rahman Md M, Alexander P, Sutherland D, Samaratunga M, Rijal BP. HIVIAIDS and HIVI TB Co-epidemic within SAARC Region Countries - Why are SAARC Countries at Risk? STC Newsletter 2002;2:22-27

4. WHO, fightAIDS, fight TB, and fight now information pack, 2004 distributed in stop TB partner's forum, New Delhi. 25 $5^{\text {th }}$ march 2004.

5. Anthony $\mathrm{H}$, Dermot $\mathrm{M}$, Lee JW et al. TB/HIV a clinical manual. WHO Geneva. $2^{\text {nd }}$ ed., 2004.

6. Cheesbroung M. District Laboratory Practice in Tropical countries. Volume II, $1^{\text {st }}$ ed., Cambridge University Press, 2002;71-211. 
7. Jha KK, Shrestha L, Karki KB, Piryani RM, Rahman MM. HIV prevalence among diagnosed TB patients - A cross-sectional study in Nepal - 2005. SAARC J Tuber Lung Dis HIVIAIDS 2006;3:60-4.

8. Misra, SN, Sengupta D, Satpathy SK. AIDS in India: recent trends in opportunistic infections. Southeast Asian J Trop Med Public Health 1998;29:373-76.

9. Subedi BK. HIV/TB Co-infection in Nepal. J Institute Med 2003;25:19-21.

10. Ghimire P, Dhungana JR, Bam DS, Rijal B. Tuberculosis and HIV Co-infection status in United Mission Hospital, Tansen Western Nepal. SAARC J Tuber Lung Dis HIVIAIDS 2004;1:32-8.
11. Situational analysis of TB/HIV collaboration at Kaski district, Nepal. Health Research and Social Development Forum (HERD), Kathmandu, Nepal 2009.

12. Bhattacharya MK, Sarkar SK. Prevalence of TB among HIV positive individuals in Calcutta. National institute of cholera and enteric diseases, $p$-33, CIT Calcutta. http://202.136.7.26/pub/publication.jsp? Classification ID= 1 \& pub med ID=4572. 